Калатур M.В., кандидат юридических наук, доцент, докторант

Национальной академии внутренних дел

\title{
СУЩНОСТЬ ПОНЯТИЯ ОПТИМИЗАЦИИ ПОКАЗАТЕЛЕЙ ОЦЕНКИ СЛУЖЕБНОЙ ДЕЯТЕЛЬНОСТИ СЛЕДСТВЕННЫХ ОРГАНОВ
}

Аннотация. В статье обоснована актуальность оценки служебной деятельности следственных органов и оптимизации ее показателей. Проанализированы и обобщены теоретико-правовые подходы к пониманию сущности понятий оптимизации, оценки, показателей оценки, служебной деятельности и тому подобное. Определена сущность понятия оптимизации показателей оценки служебной деятельности следственных органов в соответствии с подследственностью уголовных преступлений по УПК Украины.

Ключевые слова: оптимизация, оценка, показатель оценки, служебная деятельность, следственные органы, подследственность, КПК Украины.

Постановка проблемы. Служебная деятельность следственных органов является особой, исходя из специфики ее административно-правового статуса и условий, при которых она производится, - переменных, нестабильных, рискованных, усиленных и тому подобное. В то же время не вызывает сомнений, что эффективность деятельности следственных органов при любых условиях требует объективной, беспристрастной, справедливой и научно обоснованной оценки. Это, в свою очередь, обусловливает необходимость определения сущности оптимизации показателей оценки служебной деятельности следственных органов в соответствии с подследственностью уголовных преступлений по УПК Украины.

Анализ последних исследований и публликаций. Проблематику оценки деятельности правоохранительных органов и, в частности, следственных органов, критериев эффективности их служебной деятельности изучали Н.И. Ануфриев, А.М. Бандурка, А.А. Банчук, В.И. Борисов, Е.Ю. Захаров, В.С. Зеленецкий, Н.И. Иншин, Т.Е. Кагановская, Н.В. Каминская, Е.А. Крапивин, Н.П. Матюхина, И.В. Охрименко, А.М. Сердюк, В.А. Соболев, В.М. Тертишник и другие.

Нерешенные ранее проблемы. Однако, сущность именно оптимизации показателей оценки служебной деятельности следственных органов в соответствии с подследственностью уголовных преступлений по УПК Украины, остается практически неисследованной, что обусловливает актуальность и своевременность дальнейшего теоретического исследования данного вопроса.

Целью данной статьи является определение сущности понятия оптимизации показателей оценки служебной деятельности следственных органов в соответствии с подследственностью уголовных преступлений по УПК Украины.

Изложение основного материала. На сегодня в юриспруденции все чаще уделяется внимание проблемам оценки деятельности государственных органов и, что особенно актуально, правоохранительных органов. Разделяем мнение ученых, которые утверждают, что трудно переоценить значение правильной и объективной оценки деятельности именно органов досудебного расследования, как для надлежащей ее организации, так и для самих правоприменителей, деятельность которых оценивается. Поскольку и действующая система такой оценки содержит ряд недостатков, из-за чего нельзя адекватно воспроизвести результативность деятельности органов уголовного преследования, а значит, и оперативно реагировать на пробелы в их деятельности [1, с. 211].

Стоит заметить, что в Украине достаточно длительное время механизмы, по которым оценивались результаты работы, деловые и профессиональные качества, проявленные работниками при исполнении служебных обязанностей, не обеспечивали достижения целей, основываясь только на субъективном выводе руководителя и субъективной самооценке $[2$, c. 46]. Целью и конечным результатом управленческой деятельности в системе государственного управления в Украине до недавнего времени считалось управляющее воздействие, а не его результат, тогда как в странах Западной Европы и США в основу оценки деятельности публичной службы положен конечный результат. Основная проблема при использовании процедуры оценивания была связана с формальностью использования (недейственностью) процедур оценки служебной деятельности и их низкого влияния на прохождение службы и повышения результативности деятельности служащих и органов власти в целом [3]. В связи с этим в процессе реформирования правоохранительных органов и их следственных подразделений был взят курс на отмену системы «палочковой» оценки, то есть оценки только по количественным показателям, и ориентацию на результат.

Критерии или показатели оценки деятельности правоохранительных органов обусловлены содержанием желаемых результатов, целей осуществления такой деятельности, ее перспективными последствиями [1, с. 121, 131]. Поэтому поиск оптимального решения является важной задачей, как и в любой другой сфере административно-правовых отношений. В то же время оптимизация невозможна без понимания непосредственно сущности оптимизации, ее общих принципов и характерных черт. Поэтому считаем целесообразным обратить внимание, прежде всего, на указанные аспекты.

Так, в общем понимании оптимизация (от лат optimum наилучший) заключается в нахождении наилучшего варианта; является процессом предоставления чему-то выгодных характеристик, соотношений. Причем задача оптимизации считается сформулированной, если заданы критерии оптимальности; 
параметры, которые варьируются и изменение которых позволяет воздействовать на эффективность процесса; ограничения, связанные с экономическими и конструктивными условиями, и другое [4].

Оптимизация - это совокупность процессов, направленных на модернизацию и улучшение существующих механизмов достижения желаемого результата [5]. Это процесс нахождения экстремума (глобального максимума или минимума) определенной функции или выбора наилучшего (оптимального) варианта из множества возможных путем сравнительной оценки всех возможных вариантов (альтернатив) [6]. Это максимизация или минимизация определенного полезного результата (цели, целевой функции, критерия эффективности и так далее) за счет «оптимального» распределения имеющихся ресурсов [7]. Соответственно, термин «оптимальный» согласно словарю украинского языка употребляется в значении «который наиболее соответствует определенным условиям, требованиям; лучший из возможных» [8, с. 732]. Как видим, оптимизацию можно применять практически в любой сфере деятельности.

Стоит отметить, что результаты любых практических мероприятий характеризуются определенными показателями (расходы, время и так далее). И, рассматривая конкретную задачу оптимизации, устанавливают, может ли в качестве целевой функции (критерий оценки) быть принят один из показателей, характеризующих ожидаемые результаты реализации того или иного варианта, при условии, что на численные значения других показателей наложены некоторые ограничения. Кроме того, сравнивая варианты, необходимо учитывать различные неопределенности, в том числе неопределенность условий, при которых будет реализован тот или иной вариант. Поэтому, чтобы среди большого числа рациональных вариантов найти оптимальный, нужна информация о превосходстве различных сочетаний значений показателей, характеризующих варианты. И при отсутствии этой информации лучший вариант из числа рациональных выбирает руководитель, ответственный за принятие решения [6].

Полностью согласны с тем, что в данном контексте принципиально важно понимать: если нет цели, не определено, какой результат хотим получить, то нет и оптимизации. Более того, оптимизация - это не любое улучшение, а достижение наилучшего возможного в существующих условиях результата. Оптимизация всегда является выбором одного из немногих имеющихся (возможных) вариантов и предполагает наличие критериев выбора. Соответственно постановка задачи оптимизации всегда должна предусматривать четкое определение: 1) целевого показателя или показателей, для которых нужно получить наилучшие возможные значения; 2) допустимых значений показателей, которыми можно управлять для достижения желаемого результата; 3) методик измерения всех указанных показателей [7].

Причем решение реальных задач оптимизации связано с необходимостью учета ряда аспектов, среди которых: 1) отсутствие или неточность доступной информации (на практике невозможно четко описать условия, которые существенно влияют на систему, и сформулировать желаемые результаты, данные могут содержать статистические погрешности, могут быть искажены из-за особенностей методик измерений или через сознательные действия поставщиков информации и такое прочее); 2) тип, объем и структура имеющихся данных (данные могут быть: качественными, порядковыми или количественными; непрерывными или дискретными; однородными или неоднородными; смешанными и так далее); 3) временной горизонт планирования (системы, которые мы оптимизируем, в большинстве случаев - динамические, могут достаточно быстро меняться со временем так же, как и внешние условия); 4) инерционность системы, которая оптимизируется (от управленческого решения или изменения какого-либо из внешних факторов к изменениям на выходе иногда могут проходить не годы, а десятилетия); 5) для кого решение будет оптимальным, или кто принимает решение (разные люди по разным группам интересов могут иметь разные представления о том, что хорошо и что плохо, какие цели являются главными, и какие - второстепенными); 6) количество критериев оптимальности (реальные задачи оптимизации является многокритериальными, могут быть противоречивыми, когда улучшение одного показателя непременно ведет к ухудшению другого; недостаточно улучшить только один из многих показателей и не обращать внимания на другие); 7) ограничения на управляемые и другие параметры (финансовые и материальные ресурсы, кадры, сроки выполнения и так далее) [7].

Итак, в целом под оптимизацией считаем целесообразным понимать процесс нахождения (достижения) наилучшего из возможных вариантов (результатов), исходя из избранных цели и критерия оптимальности с учетом имеющихся требований, ограничений, обстоятельств и условий.

Для того чтобы определить сущность понятия собственно оптимизации показателей оценки служебной деятельности следственных органов, следует выяснить сущность и таких базовых категорий, как оценка, показатель, оценка служебной деятельности. Так, оценка - это мнение, рассуждение о качестве, характере, значении и так далее кого-, чего-либо; оценивание - составление представления, формирование заключения; определение качества, ценности, достоинств, сути, характера, значения, роли [9, с. 828]. Оценка деятельности является одновременно планомерной деятельностью руководителей и специалистов по управлению кадрами (персоналом), нацеленной на контроль качества функционирования органа (организации) и его персонала с целью получения ожидаемых результатов $[10$, c. 8$]$, и важной процедурой HR-менеджмента (управление человеческими ресурсами), которая путем установления и использования одинаковых критериев и подходов имеет существенный потенциал для влияния на эффективность, прозрачность, справедливость, условия труда $[11$, с. 1].

В свою очередь, показатель - это свидетельство, доказательство, признак чего-либо; наглядные данные о результатах какой-то работы, какого-то процесса; данные о достижениях в чем-либо [12, с. 10]. С другой точки зрения, показатели оценки являются признаками, сторонами, проявлениями управления, анализируя которые можно определить уровень и качество управления, его соответствие потребностям и интересам общества $[13$, с. 154$]$.

Исходя из вышесказанного, показатель оценки в контексте исследования уместно трактовать как данные о качестве и значение результатов служебной деятельности.

В свою очередь, служебная деятельность - это непрерывное, активное, согласованное по целям, задачам, месту и времени выполнение определенных задач [14]. Задачи и ключевые показатели результативности, эффективности и качества слу- 
жебной деятельности должны отражать конечный результат, на достижение которого направлена служебная деятельность [15].

Стоит заметить, что согласно ст. 44 Закона «О государственной службе» от 10 декабря 2015 № 889-VIII «Оценка результатов служебной деятельности» результаты служебной деятельности государственных служащих ежегодно подлежат оценке для определения качества выполнения поставленных задач, а также с целью принятия решения о премировании, выявления потребности в профессиональном обучении и так далее. Оценка результатов служебной деятельности производится на основании показателей результативности, эффективности и качества, определенных с учетом должностных обязанностей государственного служащего, а также соблюдения им правил этического поведения и требований законодательства в сфере предотвращения коррупции [16].

Типовой порядок проведения оценки результатов служебной деятельности государственных служащих утвержден Кабинетом Министров Украины. В соответствии с Типовым порядком оценкой является определение качества выполнения государственным служащим поставленных задач, а также принятие решения о его премировании, планировании служебной карьеры, определении потребности в профессиональном обучении. Оценка проводится с соблюдением принципов объективности, достоверности, доступности и прозрачности, взаимодействия и уважения достоинства. В свою очередь, задачи и ключевые показатели определяются с учетом стратегических документов государственного уровня. Положения о государственном органе должны отражать конечный результат, на достижение которого направлена служебная деятельность государственных служащих, и измеряться в количественном и / или качественном выражении [17].

Как видим, оценка служебной деятельности заключается в механизме установления результативности, эффективности и качества выполнения поставленных задач в целях служебной деятельности.

Выводы. Подытоживая выше сказанное, предлагаем определить сущность понятия оптимизации показателей оценки служебной деятельности следственных органов в соответствии с подследственностью уголовных преступлений по УПК Украины как процесс нахождения наилучшего из возможных альтернативных вариантов установки и отображения качественных и количественных данных о качестве, значении, эффективности и результативности выполнения поставленных задач в соответствии с целями служебной деятельности следственных органов и подследственности им уголовных правонарушений, исходя из избранных цели и критерия оптимальности с учетом имеющихся требований, ограничений, обстоятельств и условий.

\section{Лuтература:}

1. Проблеми забезпечення ефективності діяльності органів кримінального переслідування в Україні: монографія / кол. авт.; за заг. ред. В.І. Борисова, В.С. Зеленецького. Х.: Право, 2010. 396 с.

2. Слюсаренко О. Проблема справедливого оцінювання компетентності державних службовців для забезпечення їх професійного і кар'єрного розвитку. Вісник НАДУ. 2006. № 3. С.46-57.

3. Система оцінювання ефективності роботи держслужбовців зміниться. URL: https://www.kmu.gov.ua/ua/news/sistemaocinyuvannya-efektivnosti-roboti-derzhsluzhbovciv-zminitsya.

4. Оптимізація. Матеріал з Вікіпедії - вільної енциклопедії. URL: https://uk.wikipedia.org/wiki/\%D0\%9E\%D0\%BF\%D1\%82\%D0\%B8 \%D0\%BC\%D1\%96\%D0\%B7\%D0\%B0\%D1\%86\%D1\%96\%D1\%8F.
5. Що таке оптимізація. URL: https://www.taina.com.ua/shho-takeoptymizacija/.

6. Солнишков Ю.С. Оптимізація. URL: http://vseslova.com.ua/word/ $\%$ D0 $\% 9$ E $\%$ D0 $\%$ BF $\%$ D $1 \% 82 \%$ D0\%B8\%D0\%BC $\%$ D1\%96\%D0\% B7\%D0\%B0\%D1\%86\%D1\%96\%D1\%8F-75289u.

7. Бахрушин В. Оптимізація і «оптимізація» в освіті та управліннi. URL: http://education-ua.org/ua/articles/724-optimizatsiya-ioptimizatsiya-v-osviti-ta-upravlinni.

8. Словник української мови: в 11 томах. Том 5, К.: Наукова думка, $1974.840 \mathrm{c}$

9. Словник української мови: в 11 томах. Том 5 / АН УРСР. Інститут мовознавства; за ред. І.К. Білодіда. К: Наукова думка, 1974. 840 с.

10. Сучасна технологія оцінювання персоналу та кадрового потенціалу організації і її соціально-психологічний аспект: наук. розробка / авт. кол.: В.М. Мартиненко, Ю.Д. Древаль, Ю.В. Конотопцева та ін. К.: НАДУ, 2013. 52 с.

11. Рекомендації щодо вдосконалення процедури оцінювання результатів службової діяльності державних службовців. URL: http://www.ucs-hrm.org.ua/ocinyuvannya-diyalnostiderzhsluzhbovciv/view-category.html.

12. Словник української мови: в 11 томах. Том 7 / АН УРСР. Інститут мовознавства; за ред. І.К. Білодіда. К: Наукова думка, 1976. 723 с.

13. Мельник А.Ф., Оболенський О.Ю., Васіна А.Ю., Гордієнко Л.Ю. Державне управління: навч. посіб. / за ред. А.Ф. Мельник. К.: Знання-Прес, 2003. 343 с.

14. Термин «Службова діяльність підрозділів». Перечень терминов. URL: http://zakon.rada.gov.ua/laws/term/ru/35582?lang=ru.

15. Тищишина А. Оцінювання результатів службової діяльності: етапи і приклади. Держслужбовець. 2017. №11. URL: https:// i.factor.ua/ukr/journals/ds/2017/november/issue-11/article-32053.html.

16. Про державну службу: Закон України від 10 грудня 2015 року № 889-VIII. Відомості Верховної Ради. 2016. № 4. Ст.43.

17. Постанова Кабінету Міністрів України від 23 серпня 2017 р. № 640 «Про затвердження Типового порядку проведення оцінювання результатів службової діяльності державних службовців». URL: http://zakon.rada.gov.ua/laws/show/640-2017-\%D0\%BF.

Калатур М. В. Сутність поняття оптимізації показників оцінки службової діяльності слідчих органів

Анотація. У статті обгрунтована актуальність оцінки службової діяльності слідчих органів і оптимізації іï показників. Проаналізовано та узагальнено теоретико-правові підходи до розуміння сутності понять оптимізації, оцінки, показників оцінки, службової діяльності тощо. Визначено сутність поняття оптимізації показників оцінки службової діяльності слідчих органів відповідно до підслідності кримінальних злочинів за КПК України.

Ключові слова: оптимізація, оцінка, показник оцінки, службова діяльність, слідчі органи, підслідність, КПК України.

Kalatur M. The essence of the concept of optimization of performance assessment indicators of investigative authorities

The article substantiates the relevance of the assessment of the work of investigating authorities and the optimization of its indicators. The theoretical and legal approaches to understanding the essence of the concepts of optimization, evaluation, evaluation indicators, service activities, etc. are analyzed and generalized. The essence of the notion of optimization of indicators of evaluation of official activity of investigating bodies in accordance with the investigation of criminal offenses under the CPC of Ukraine is determined.

Key words: optimization, estimation, estimation index, service activity, investigation bodies of inquiry, CPC of Ukraine. 